\section{Renal failure due to cholesterol embolisation}

Sir

In their report of five cases of renal failure due to cholesterol embolism, Khan et al succinctly review the clinical and pathological findings of the syndrome of cholesterol crystal embolisation. A further review of the literature reveals that the syndrome is described as rare ${ }^{2}$ or common, ${ }^{3}$ depending on the clinical criteria used to make the diagnosis. Confirmation of the diagnosis can be made by biopsy of skin or muscle, ${ }^{4}$ but is probably reserved for cases where the diagnosis is in doubt. This may explain the relative lack of large series described in the literature. ${ }^{5}$

In my experience in two Canadian centres, Toronto and Ottawa, where large numbers of invasive vascular procedures are performed, acute renal insufficiency due to cholesterol crystal embolisation is quite common, in contrast to the apparently low incidence in the UK. Indeed, the nephrology service may make this diagnosis as frequently as twice monthly, though biopsy is rarely undertaken. This almost certainly reflects the relatively low threshold for consultation of subspecialty services in Canada as compared with the UK. Here, consultation is frequently requested for minor degrees of renal insufficiency, both chronic and evanescent, to provide educational input for the parent specialty.

Accordingly, given the frequency with which this clinical diagnosis is made in Canada, one must concur with the authors that many subclinical cases remain undiagnosed. This may reflect differences in philosophy with respect to requesting subspecialty consultation across the Atlantic.

NB ARGENT Division of Nephrology, Ottawa General Hospital, 501 Smyth Road, Ottawa K1H 8L6, Canada

1 Khan MA, Hattersley J, Furness PN, et al. Renal failure due to cholesterol embolisation. Postgrad Med $f$ 1995; 71: 107-9.

2 Rosansky SJ, Deschamps EG. Multiple choleRosansky Sol, Deschamps EG. Multiple chole-
sterol emboli syndrome after angiography. $A m \mathcal{F}$ sterol emboli syndrome af

3 Mamirez G, O'Neill WM, Lambert R, Bloomer HA. Cholesterol embolization, a complication of angiography. Arch Intern Med 1978; 138: 1430-2.

4 Fine MJ, Kapoor W, Falanger V. Cholesterol crystal embolization: a review of 221 caases in the English literature. Angiology 1987; 38: 769-84. 5 Om A, Ellahham S, DiSciascio G. Cholesterol embolism: an underdiagnosed clinical entity. $A m$ Heart $₹$ 1992; 124: 1321-5.

\section{ACE inhibitors in heart failure. What dose?}

Sir,

The variability in dose regimes for angiotensin-converting enzyme (ACE) inhibitors in heart failure, highlighted by Cleland $e t a l,{ }^{1}$ has indeed been long overdue for scientific analysis, so as to enable rational choice of the optimum dose. Likewise, the time is ripe for rationalisation of selection criteria for ACE blockade in heart failure, now that we have become aware of the heterogenicity of left ventricular dysfunction in the participants of the CONSENSUS I trial. ${ }^{2}$ According to subgroup analysis, the only patients in that trial who obtained significant survival benefit from enalapril were those with left ventricular systolic dysfunction, defined as $\left\langle 14^{\circ}{ }_{0}\right.$ fractional shortening of the left ventricle. ${ }^{2}$ Patients with intact left ventricular systolic function had a relatively good prognosis, which was not significantly improved by co-prescription of enalapril. Trials addressing the issue of survival benefit in left ventricular diastolic failure would therefore need to recruit vast numbers of patients, cognisance being taken of the co-existence of conditions such as hypertension and recent myocardial infarct, characterised by stigmata such as left ventricular hypertrophy and left ventricular remodelling, respectively, which respond well to ACE-blockade. ${ }^{3,4}$ Tameside General Hospital, Ashton under Lyne, Lancs OL6 9RW

1 Cleland JGF, Hubbard WN, Pittard J, PooleWilson PA, Sutton GC. ACE inhibitors in heart failure. What dose? Postgrad Med $\mathcal{f}$ 1995; 71: 65-6.

2 Eriksson SV, Kjekshus J, Offstad J, et al. Patient characteristics in cases of chronic severe heart failure with different degrees of left ventricular systolic dysfunction. Cardiology 1994; 85: 137-44.

3 Materson BJ, Preston RA. Angiotensin-converting enzyme inhibitors in hypertension. A verting enzyme inhibitors in hypertension. A dozen years of experi

4 Vannan MA, Taylor DJE. Ventricular remodelling after myocardial infarction. Br Heart $\mathcal{f}$ 1992; 68: 257-9.

\section{Cigarette smoking and sore throats in adults}

Sir,

The perils of cigarette smoking, both active and passive are well recognised. Much importance has been given to the effects of passive exposure to tobacco smoke on the air passages, particularly in children. Studies carried out two decades ago have shown a definite association between exposure to cigarette smoke and the incidence of upper and lower respiratory infections in children. ${ }^{1,2}$ More recently, a relationship between parental cigarette smoking and adenoidectomy and tonsillectomy in children has also been demonstrated. ${ }^{3,4}$ The effects of passive smoking on the respiratory tracts of children have been attributed to the breakdown of the integrity of the respiratory mucosa and defective ciliary clearance as well as greater stresses imposed upon the airways due to a relatively increased airflow. ${ }^{3}$ However, the association between cigarette smoke and sore throats in adults does not appear to have been studied.

We report on a case-control study comprising 109 adults (age range 16-45 years) who underwent tonsillectomy for recurrent sore throats during a 12-month period and 118 age-matched controls who still retained their tonsils. A detailed questionnaire was sent to patients in both groups. This elicited inform-

\section{Cigarette smoke and pharyngeal symptoms}

- effects more pronounced in children

- similar frequency of sore throats in smokers and non-smokers

- higher incidence of lower respiratory tract illness in smokers

ation on smoking habits, including quantity and duration of smoking and exposure to passive smoking. A detailed history of sore throats was also obtained in the control group. The episodes of sore throats considered significant were those requiring antibiotic treatment from the patients' general practitioners. Although there were proportionately more active smokers amongst cases $\left(37^{\circ}{ }_{0}\right)$ than controls $\left(25^{\circ}{ }_{0}\right)$, this was not statistically significant using the chi-squared test $(\chi=3.4 ; \mathrm{df}=1 ; \mathrm{p}<0.10)$. The incidence of passive smoking in both groups was approximately $45^{\circ}{ }_{0}$. The quantity and duration smoked were also closely matched in both groups. Within the control group, there was no statistically significant difference in the frequency of sore throats between smokers and non-smokers.

The deleterious effects of cigarette smoke on the pharyngeal mucosa have been shown to be due to alteration of the oropharyngeal flora with increased carriage of Haemophilus influenzae. ${ }^{5}$ In a study comprising a large group of young adults, smokers were found to have a statistically significant greater likelihood of having a lower respiratory tract illness than non-smokers. ${ }^{6}$ This is probably related to the effect of tobacco smoke on the ciliated columnar epithelium resulting in a metaplasia to a more secretory type with subsequent ciliary dysfunction. However, the oropharyngeal mucosa which is lined by a hardier stratified squamous epithelium is likely to be subjected mainly to an irritative effect by tobacco smoke. This may lead to a slight increase in the prevalence of sore throats amongst smokers but as demonstrated by our study, the difference is unlikely to reach levels of significance.

P MURTHY MR LAING

Department of Otolaryngology Raigmore Hospital NHS Trust, Inverness IV2 3Uf, UK

1 Colley JRT, Holland WW, Corkhill RT Influence of passive smoking and parental phlegm on pneumonia and bronchitis in early phlegm on pneumonia and bronch

2 Harlap S, Davies AM. Infant admission to hospital and maternal smoking. Lancet 1974; 1: pital and

3 Willatt DJ. Children's sore throats related to parental smoking. Clin Otolaryngol 1986; 11 317-21.

4 Hinton AE, Herdman RCD, Martin-Hirsch D Saeed SR. Parental cigarette smoking and tonsillectomy in children. Clin Otolaryngol 1993; 18 178-80.

5 Dilworth JP, White RJ, Brown EM. Oropharyngeal flora and chest infection after upper abdominal surgery. Thorax 1991; 46: 165-7.

6 Aronson MD, Weiss ST, Ben RL, Komaroff AL. Association between cigarette smoking and acute respiratory tract illness in young adults. $\mathscr{J} A M A$ 1982; 248: $181-3$ 